\title{
Effect of Odor Stimulation According to E-Book Reading
}

\author{
Seung-Hyun Kwak(ecoterran@gmail.com) ${ }^{1}$, Byung-Chan Min (bcmin@hanbat.ac.kr) ${ }^{2}$ \\ ${ }^{1}$ Department of Industrial \& Management Engineering, Hanbat National University, San 16-1,Duckmyung-dong, \\ Yusung-gu Daejeon, 35408, \\ ${ }^{2}$ Corresponding author : Department of Industrial \& Management Engineering, Hanbat National University, San
}

16-1,Duckmyung-dong, Yusung-gu Daejeon, 35408

\begin{abstract}
This study aimed to find out whether the reading fatigue by an e-book can be relieved through the stimulation of Lavender odor which has a relaxing effect. The experiment was conducted the subjects of 15 men and women in their twenties who had no olfactory disorders, Photoplethysmography(PPG) was measured for the fatigue, and the subjective assessment was conducted for the subjective fatigue. As the result of the experiment, the fatigue was lower when e-books were read in the condition where Lavender odor was presented than when only e-books on a smart phone were read, where there was a significant difference $(\mathrm{p}<0.1)$. Therefore, as the result of the experiment in this study, given the effect of Lavender odor, the structure of a brain, and the cerebral acting region of sight and smell of the previous studies comprehensively, it is supposed that the increase in visual fatigue due to e-book reading outpaces the relaxing effect of Lavender odor which is absorbed through smell. It is judged that there should be many studies on the interaction on the cerebral capacity of sight and smell in the future.
\end{abstract}

Keywords: E-book, Reading, Odor, Fatigue, PPG

\section{Introduction}

There are many things using a smartphone such as MP3, electronic dictionaries, web surfing and so on. So, the number of users of the smartphone has been constantly increasing.

In case of e-books, many applications are being developed to make it easier to read for smartphone.

Therefore, the interest of readability and reading of fatigue between paper book and e-book is increasing.

In the study on reading of fatigue in comparison with the eye blink, it is proved that in case of the reading e-book, the number of eye blink is more than in case of the reading paper book (Kim et al., 2012).

This mean that in case of reading e-book visual fatigue has greater. Studies related to visual fatigue have been actively studied since the 1980s when CRT (Cathod Ray Tube) displays were introduced into office work. (Park et al., 1994)

Recently, due to the increase of public interest in 3D, 3D TV has become popular and many researches about visual fatigue due to $3 \mathrm{D}$ image are being announced.

There are many difficulties in objectively measuring the degree of fatigue because of the individual differences. However, objective measurement methods for visual fatigue are being investigated through a physically-based approach, such as muscle movement associated with the eye and frequent use of optic nerve causes of visual fatigue (Park et al., 1994). In recent years, methods of measuring visual fatigue based on bio signal analysis such as EEG, ECG, and PPG have also been actively studied.

Study on the fatigue of e-books and paper books are active, but the study of the visual fatigue reduction is small. because in order to identify the root cause of visual fatigue, it is necessary to research on complex brain structure and the optic nerve system. But it is not easy.

In this study, instead of approaching to identify the source of a visual fatigue, and provide direction to solve this problem, by applying existing fatigue reduction and related factors identified in previous research on visual fatigue state through experiment and evaluate whether those factors are contributing to eased fatigue.

Lavender is known to relieve anxiety, stress and fatigue by lowering the sympathetic nervous system activation. (Min, 2001) So, the purpose of this study is that to know the lavender oil scent effect on fatigue caused by reading e-books through the autonomic nervous system changes. 


\section{Method}

The purpose of this study was to investigate whether reading fatigue by electronic books can be alleviated through the presentation of lavender scent with sedative effect.

The experiment was conducted on two subjects per day, and the presentation order of fragrance was divided into two groups.

\subsection{Participants}

The participants where 10 students in 20's who do not have cardiovascular diseases, herbal incense allergy and visual disorder.

\subsection{Test Environment}

As for the lab environment, room temperature was maintained at $25 \pm 2{ }^{\circ} \mathrm{C}$, and the humidity was $35 \sim 52 \%$. Vital Meter, which is manufactured by TAOS Institute in Japan, was used to measure the pulse wave. The sampling frequency was $1 \mathrm{kHz}$. Vital Meter measures earlobe pulse waves and is wireless.

The $100 \%$ lavender oil used in this test were manufactured by KIMEX Co. (Korea)

\subsection{Test Procedure}

Test procedure was as shown in Figure 1.

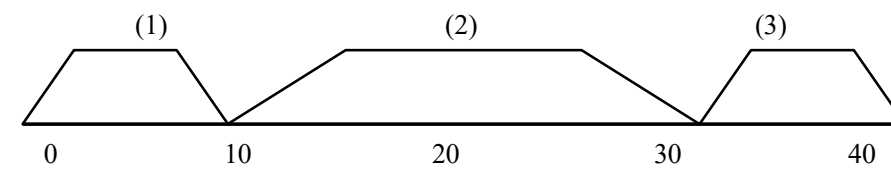

\section{Results}

For the analysis of the experimental results, a paired t-test was conducted for the LF / HF ratio between when reading e-books while presenting lavender scent and reading e-books only.

As a result, in group $\mathrm{A}$, the $\mathrm{LF} / \mathrm{HF}$ ratio when reading an e-book with lavender incense is statistically significant less than LF / HF ratio when reading an e-book only at 0 to 3 minutes after the start of the experiment $(\mathrm{P}<0.1)$.

However, there was no statistically significant difference in the LF / HF ratio when the lavender scent was presented nervous system when reading an e-book only and e-books in presented fragrance of lavender oil. After the

break and were read e-books in presented fragrance of der oil. measure subjective fatigue and concentration.

In order to measure the subjective fatigue, 7 point likert scale was used. To measure the concentration, five number of correct answers was used for the analysis.

The lavender scent was placed $15 \mathrm{~cm}$ away from the subject's nose, and the smell was held for 90 seconds. After closing the bottle cap, the experiment was conducted in the remaining fragrance state.

\begin{tabular}{|c|c|c|c|c|}
\hline (1) & (2) & (3) & (4) & (5) \\
\hline & $\begin{array}{l}\text { Physiological signal measuring } \\
\text { section }\end{array}$ & & $\begin{array}{l}\text { Physiological signal measuring } \\
\text { section }\end{array}$ & \\
\hline $10 \mathrm{~min}$ & $20 \mathrm{~min}$ & $10 \mathrm{~min}$ & $20 \mathrm{~min}$ & $10 \mathrm{~min}$ \\
\hline Questionnaire & Lavender scent $+\mathrm{e}$-book & $\begin{array}{c}\text { Rest+ } \\
\text { Questionnaire }\end{array}$ & $e^{- \text {book only }}$ & Questionnaire \\
\hline & $\begin{array}{l}\text { Physiological signal measuring } \\
\text { section }\end{array}$ & & $\begin{array}{l}\text { Physiological signal measuring } \\
\text { section }\end{array}$ & \\
\hline $10 \mathrm{~min}$ & $20 \mathrm{~min}$ & $10 \mathrm{~min}$ & $20 \mathrm{~min}$ & $10 \mathrm{~min}$ \\
\hline Questionnaire & e-book only & $\begin{array}{c}\text { Rest }+ \\
\text { Questionnaire }\end{array}$ & Lavender scent $+\mathrm{e}$-book & Questionnaire \\
\hline
\end{tabular}

Figure 1. Test Procedure 
In Group B, there was no statistical difference in the LF / HF ratio when reading e-books while reading between only e-books and lavender scents.

The results of the group A is shown in Figure 2.
In order to study the effect of the incense on the relaxation of visual fatigue,

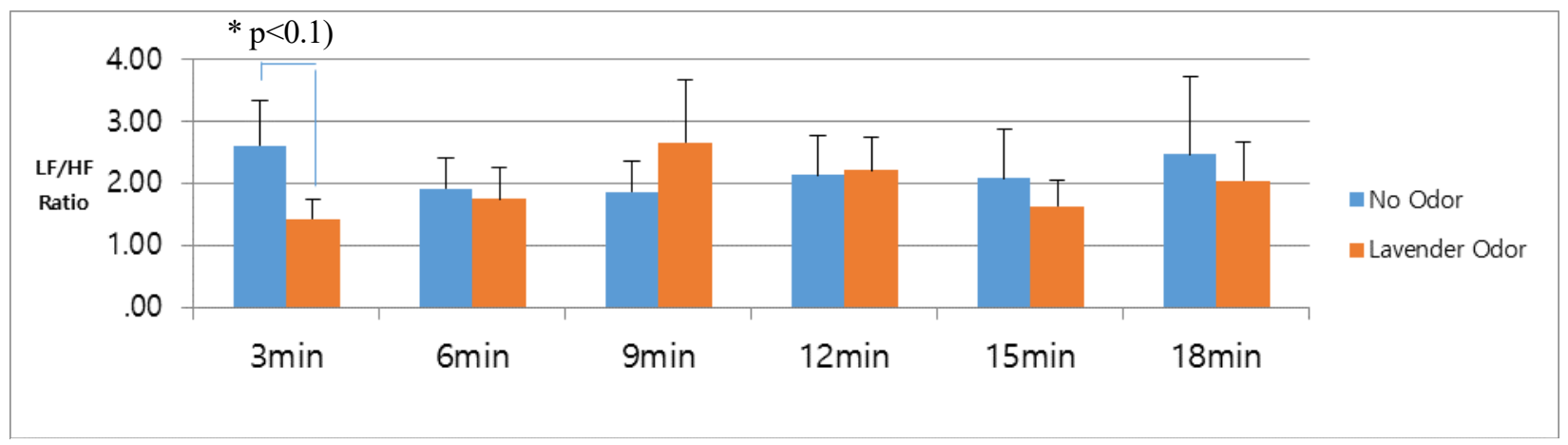

Figure 2. Test Changes in LF/HF Ratio according to the division of time Design in Group A

In the results of the questionnaire survey on the subjective fatigue and concentration in the 10-minute break, in the case of subjective fatigue, the average of the subjective fatigue when the lavender scent was presented was 4.4 .

This the visual fatigue was lower than the average of 4.7 when the lavender scent was not presented, but no statistically significant difference occurred.

In the case of concentration, the average was 3.7 when the lavender scent was presented and the average was 3.2 when the lavender scent was not presented. So the concentration of subjects in the state of lavender scent was higher. But this was not statistically significant either.

The results are shown in Table 1.

Table 1. The difference of subjective fatigue and concentration according to the presentation of lavender scent

\begin{tabular}{c|c|c|c|c}
\hline \multirow{2}{*}{} & \multicolumn{2}{|c|}{ Fatigue } & \multicolumn{2}{c}{ Concentration } \\
\cline { 2 - 5 } & $\begin{array}{c}\text { e-book } \\
\text { only }\end{array}$ & $\begin{array}{c}\text { Lavender } \\
\text { scent }+ \\
\text { e-book }\end{array}$ & $\begin{array}{c}\text { e-book } \\
\text { only }\end{array}$ & $\begin{array}{c}\text { Lavender } \\
\text { scent }+ \\
\text { e-book }\end{array}$ \\
\hline Avg. & 4.7 & 4.4 & 3.2 & 3.7 \\
\hline
\end{tabular}

The experiment was to read the e-book for 20 minutes in case between without lavender scent and lavender scent presented.

The purpose of this study is to verify whether the recovery of visual fatigue is faster when lavender scent is presented than when the fragrance is not presented.

Experimental results showed different results depending on the presentation order of fragrance.

In Group A, reading the e-book with the lavender scent first, and after a 10-minute break, reading only e-books. A paired t-test was performed on the LF / HF ratio of each experimental result.

And, In the case of Group B, after reading the e-book without lavender incense and reading the e-book with lavender scent for 10 minutes, paired t-test was performed for each LF / HF ratio.

The LF / HF ratio was significantly lower in the group A than 0 to 3 minutes, so that the visual fatigue was alleviated. However, no significant difference was observed over 3 minutes.

On the other hand, in group $\mathrm{B}$, the presentation of incense did not affect the visual fatigue statistically significantly.

These results suggest that lavender oil may be effective in lowering sympathetic nervous activity, which is contrary to previous studies (Cooksley, 1996).

Visual system transmits the visual information to the cerebral cortex via the optic nerve. If the visual fatigue is accumulated, the function pathways of the visual information is generated on the degradation.

Smell is transmitted to the Central Nervous System 
through the olfactory epithelium of the nose. Smell passes information to the limbic system of the brain through the olfactory nerve.

The optic nerve and the brain is divided into 12 pairs for dual olfactory nerve is connected to the brain. Optic nerve is passed to the erebral cortex and olfactory are passed to the limbic system.

Therefore, if comprehensively taking into account the following factors: the results of this study, the effects of lavender in previous studies, structure of the brain and visual and olfactory regions of the cerebral action.

The increase in visual fatigue caused by the e-book reading could presumably more dominant than the relaxation effects of lavender oil that is absorbed through the nose.

In order to understand the interaction of the receiving mechanism of the visual and olfactory the cerebral, many studies will be required.

\section{References}

Kim, J.Y., Lee, M.H., Min, S.N., Cho, Y.J. and Choi, J.h., "Quantitative Comparison of the E-book and Paper-book by using Eye-tracker", Journal of the Ergonomics Society of Korea, 31(5), 609-616, 2012.

Park, J.H., Lee, Y.C. and Kim, Y.C., "Survey on the Measure of Visual Fatigue" Industrial Engineering \& Management Systems, Spring, 112-121, 1994.

Min B.C., "Psycho-Physiological Effect of Odors on Human Being." Korean Society for Precision Engineering, 18(2), 46-53, 2001

Worwood, Valerie Ann, "The fragrant mind: aromatherapy for personality, mind, mood and emotion”, New World Library, 2012.

Cooksley, V. G "Aromatherapy: A lifetime guide to healing with the Essential oils", New Jersey: Prentice Hall Press, 1996, 